\title{
THE IMPACT OF CULTURE AND CREATIVITY ON THE ECONOMY OF THE CITY
}

\author{
Kaspars PLOTKA ${ }^{1}$, Jānis VIRŽBICKIS ${ }^{2}$, Jānis ZVIRGZDIN̦Š ${ }^{3}$, \\ Girts ZARIN̦Š ${ }^{4}$, Sanda GEIPELE ${ }^{5}$ \\ ${ }_{1,2,4,5}$ Riga Technical University, Riga, Latvia \\ ${ }^{3}$ University of Latvia, Riga, Latvia \\ Corresponding author's email: Kaspars.Plotka@rtu.lv
}

\begin{abstract}
Creativity is an important component of the economy for modern cities, and necessary condition for it is the qualitative understanding of the economic theory science. In the global competition, it plays an important role for the economic growth dynamics, which is directly related to human resource role in the modern economy. The competitiveness of the territories depends on their attractiveness to economically active individuals and the opportunities they provide with economic growth. When considering the creative and cultural industries as potential economic development factors in the urban economy, culture can be considered as a new stage in urban development based on quality of life, creativity, which provide a level of degree for balance and determine the stability of the growth potential. The development of supporting urban infrastructure is identified as one of the drivers for expansion of the cultural and recreational domains both for the political and economic development. They reflect the specific characteristics of each city, the competitiveness versus attractiveness potential, and demonstrate the potential shift from the environment for production to a potentially new consumer environment with a higher "symbolic value". The creative industries today can serve as an urban development domain tool, creating a modern approach to economic activity in various sectors of the economy. The authors draw attention to the cluster link between creative and cultural industries in urban planning. The authors propose a methodology for assessing revenues and costs, as well as recommendations for the work of cultural organisations and institutions involved in creating a creative urban environment. The article presents data and modelling results of the economic impact calculations for two imagined cities in order to theoretically approbate the methodology, which would help assess the socio-economic effect of the development of certain clusters. The aim of the research is to identify the impact of culture and creativity on the economy of city. The calculated information for decision makers would help formulate recommendations, evaluate potential developments of the urban environment, assist in planning and networking in urban agglomerations, based on clusters of creative and cultural industries, as the post-industrial city needs to make changes in order to achieve economic growth. The development of urban cluster of creative and cultural industries has a certain multiplicative effect, i.e., impact on the development of other types of economic activity.
\end{abstract}

Keywords: Cluster, Creative Industries, Creativity, Urban Environment, Urban Product. 


\section{INTRODUCTION}

The urban cultural domain of cities was historically formed by merging a spontaneous social organization in the context of a global culture with planned city management and development, initially sourcing from the city's residential districts. A special spirit was felt in Paris, London or New York - in these bubbling art booths (they should not be confused with the practice of the Hellenistic era of systematic urban planning and the construction of cultural buildings - theaters, circuses and libraries - in united architectural ensembles with administrative buildings ("white houses") and trading areas). When comparing the rural environment and the vastness of the urban environment, one dominates nationality, while the second facilates cultural environment and is in a direct relationship with creative processes in public life. Cities became the place where the authentic cultural city intertwined with standard models and their established potential for formation (Wilson, 2002).

Research of the urban environment should focus not only on the historical development of the city, but also on the evaluation of the impact of socio-political mechanisms on the development together with cultural strategies. Analysis of the "cultural environment" should take into account not only direct social, economic and socio-anthropological research, but also history and include mechanisms related to socio-political and economic modelling of the cities.

The research "boom" of creative cities in Europe and the United States in the 1990s serves as an example of how the greatest socio-economic problems in the urban environment can be addressed through cultural strategies. Frankfurt, Glasgow, Bilbao and many other "depressive" cities began to improve their image by the use of political and economic levers of the internal and external image. Sometimes it can be identified that the principle of spatial planning (which can also be called cultural-economic planning) considered as the basis with some unconventional (creative) approach to city planning is used, by taking into account human and cultural capital of the city. An academic example of such cooperation of this approach of the urban policy is the Solomon Guggenheim Museum (New York) branch in the city of Bilbao, Spain. The museum quickly gained the interest of tourists, became a popular site and one of the strongest pillars in the region, which contributed to the prosperity of the city - economic and social growth. Scientists have emphasized that using global cultural heritage and adding it to modern artistic shape; it is possible to improve financial investment attractiveness. Using investment in culture to create a new positive image, Bilbao city followed such examples of cities as Barcelona, Frankfurt, Paris, etc. (Matarasso \& Lendry, 1999).

The term "creative economy" was initially used in the scientific texts from 2001. British scientist John Howkins (The Creative Economy, John Howkins, 2017) invented the term "creative economy". Following his concept, creative economy is well reflected in the creative business opportunities. The features of creative economy are evident in definition of the specific socio-economic relations between the economy and the artistic approach to its development and improvement. 
Eventually, according to Howkins, it has led to a new creative sector emerging in the postindustrial economy, which is based on the cultural and creative industries and their intellectual resources (Howkins, 2013).

At present, the term "creative economy" is often associated with the term "knowledge economy". It can be identified as a special economic sector based on a different type of intellectual work (Stepanov, 2013). Investment in knowledge economy is a great motivation for the attractiveness of the investment climate, which modernises science and education.

The aim of the article is to provide a method to evaluate effect of creativity impact on the urban environment economy and to develop a methodology that systematises and supports quantitative assessment of the urban environment in a given area.

The study is based on a theoretical analysis, cabinet research method, statistical analysis and mathematical modelling. Data are collected from publicly accessible databases and statistical reports.

By developing an interdisciplinary creative model for a city, the compilation of data from different cities would lead to development of the improved assessment methodology, which more precisely would indicate potential of the economic growth. Such a shared model would support relevant information exchange, thus improving cooperation between different municipalities. Urban policymakers should start to consider creativity as a driving force of the city evolution in order to develop the economic potential. Knowledge economy is a vital element, which allows developing new forms of urban development.

By developing an interdisciplinary creative model, the compilation of such data would lead to the assessment of the economic potential, the quality of experience exchange, the usefulness of the economic rationale and the delimitation of sensitive data, in accordance with the cooperation agreements and functions of the municipalities. Urban policymakers should recognise creativity as a driving force for the city in order to develop the economic potential. Creativity is an element through which the urban environment provides new forms of urban economic activity that are aimed at attracting more investment, professionals, service providers by persuading that urban areas and streets are fully suited to economic activity and development.

\section{STRATEGIC POTENTIAL OF CREATIVE AND CULTURAL INDUSTRY CLUSTER}

The authors of the paper recommend involving the following components in the cluster for assessing the potential of the creative and cultural industry cluster:

1. The employment level in the cluster, comparing it with the overall level of the city;

2. The employment growth rate in the cluster, comparing it with employment in the economy of the city;

3. The contribution of the cluster in the overall economy of city. 
The authors suggest assessing the model with use of the classification according to the general economic activity (NACE) (Statistical Classification of Economic Activities in the European Community, Rev. 2, 2017). The following ratio is calculated for each section:

$$
S=\frac{q}{Q} 100
$$

where

$S$ - the employment level in the creativity and cultural industry cluster from the total number of employees in the city's economy, \%;

$q$ - the number of employees in a particular cluster in the corresponding NACE;

$Q$ - the total number of employees in the corresponding NACE economy section of the city.

The urban clusters of the creative and cultural industries referenced in formulae 1 attribute the employment level to the common network and can be recognised with related creative and cultural activities. Specific co-operation is basis for joint synergies, where education is one of the foundations. Recognition as a common cluster or clusters can help unite creative forces (organisations or cultural spheres) and creative people (firms) in sectors such as marketing, advertising, design, mass media for better and more effective cooperation. Such city-affiliated networks allow increasing the "mass" of products and services that are related to the cultural segment, as well as creativity in the perception of society and promoting a level of perception of other actors such as companies, households, the state and local municipalities.

\section{PRODUCTS OF THE CITY}

Urban production capacity is measured by the city's product, which serves as an important indicator in comparing the growth level and development of economic urban areas with national growth rates. A city product can be measured with similar methodology as Gross Domestic Product $(G D P)$, and for a city that can be used to measure the growth rate of a city's economy. The United Nation's Habitat program (World Cities Report 2016) calculates a city product using one of two approaches: the ratio between the number of people employed in different sectors of the economy and the level of remuneration (method A), or based on revenue data of the urban households multiplied by the ratio of GDP and total household income at the national level (method B) (Kipnis, 2006). According to the Decree of the Cabinet of Ministers of the Republic of Latvia No 28 as of 28 April 2004 "On the Statistical Regions of the Republic of Latvia and the Administrative Units of the Republic of Latvia" (about the Statistical Regions of the Republic of Latvia and the Administrative Units of the Republic of Latvia, 2004), (Amendments: 3 June 2009, No. 381; 28 December 2010, No. 759) and the European Union Common Statistical Classification of Territorial Units (NUTS 3), GDP data are calculated for six statistical regions (Riga, Pieriga, Vidzeme, Kurzeme, Zemgale, and Latgale). The 
authors of the paper propose calculating the gross product of the city (GDP) according to the following methodology:

$$
G D P=R_{\mathrm{Pr}}+R_{\mathrm{Pk}},
$$

where

$G D P$ - a city's gross product;

$R_{\mathrm{Pr}}$ - total production of goods in the city;

$R_{\mathrm{Pk}}$ - total production of services in the city.

Using this method, quantitative data are collected and summarised that provide a picture of the economic scene for a specific urban area and improve the qualitative nature of the development plan. By developing an interdisciplinary creative model, the compilation of such data would lead to an assessment of the economic potential, the quality of exchange of experience, the usefulness of the economic rationale and the anonymisation of the sensitive data, in accordance with functions of the municipalities. It should not be accepted that the creative urban environment becomes a "rhetorical figure" and is used by political forces to deceive the public by stating that they are developing something new and economically viable.

Using creativity as the driving force for the city to develop its economic potential is an element through which the urban environment develops new forms of urban economic activity that are to attract more investment, professionals, service providers and convince them that the urban environment is well suited for the economic activity and change.

The development of urban cluster of creative and cultural industries has a certain level of multiplicative effect, i.e., impact on the development of other types of economic activity. According to the authors, this creates an increase in the value added to a number of economic activities in the following sections of NACE:

1) $\mathrm{F}$ - Construction;

2) $\mathrm{G}$ - Wholesale and retail trade; repair of motor vehicles and motorcycles;

3) $\mathrm{H}$ - Transportation and storage;

4) I - Accommodation and catering services;

5) J - Information and communication services;

6) L - Real estate operations;

7) $\mathrm{P}$ - Education;

8) $\mathrm{S}$ - Other services;

9) U - Extraterritorial organisations and institutions.

If the total increase in GDP per year is calculated according to formula (3), then the GDP associated with the cluster development of creative and cultural industries can be calculated from formula (4):

$$
\Delta G D P=\sum_{i=1}^{n} \Delta P V_{i}
$$

where $P V_{i}-$ added value produced in a particular NACE section; 


$$
\begin{aligned}
& \Delta G D P=\Delta P V_{\mathrm{F}}+\Delta P V_{\mathrm{G}}+\Delta P V_{\mathrm{H}}+\Delta P V_{\mathrm{I}}+ \\
& +\Delta P V_{\mathrm{J}}+\Delta P V_{\mathrm{L}}+\Delta P V_{\mathrm{P}}+\Delta P V_{\mathrm{S}}+\Delta P V_{\mathrm{U}}
\end{aligned}
$$

where $P V_{j}$ is added value produced in the relevant NACE sections by the development of creative and cultural industry clusters.

\section{CULTURE, CREATIVITY AND ECONOMICS}

As the next method for assessing the impact of creativity and culture in order to promote the development of cities and territories, the authors of the paper recommend identifying the sphere of influence of culture and creativity on the local economic development:

1) the direct economic impact on employment and the value creation by cultural industries, as well as the impact of costs, which will increase indirectly with the popularity of creative professions among those employed in the cultural sector;

2) activation of cultural industries with urban spatial planning to attract visitors (tourists), which increases travel costs and improves the local business environment;

3) creative resources that are accumulated in local production networks (in production processes and products or in organisational modules).

Representatives of the cultural and creative industries are perceived as "initiators" of the break-even cost and value-added value change. Their ideas as well the information base should be able to create new, creative and innovative sectors within the traditional economy. Human creativity sectors could be based on activity involving the mobility and speed of information exchange among persons. It can be observed in business incubators, science parks, campuses, as well as in non-governmental youth centers.

According to the authors, the following indicators can serve as indirect evidence of the creativity and culture influence on the urban economy for the reporting year:

1) the number of graduates (colleges, vocational schools, universities, and institutes) who have remained in the city;

2) the proportion of a new business activity type within urban activities that have emerged in the structure of the city;

3 ) the proportion of population aged 18-40 with higher education in the total population;

4) the proportion of young people aged 12 to 17 in the seasonal (summer) work in the city.

The socioeconomic effect from development of the creativity and the cultural sector network cluster can be analyzed in a wider scale and may be identified in longer period. The economic effect is the difference between the results of economic activity and the investment in achieving them. The economic effect 
generated by creativity and culture industries and clusters, as well as urban clusterbased networks, is assessed as follows:

$$
E=T R_{\mathrm{Cl}}+\Delta R_{\mathrm{T}}+\Delta R_{\mathrm{U}}+\Delta R_{\mathrm{I}}+\Delta R_{\mathrm{Tr}}+\Delta R_{\mathrm{Eu}}-C_{\mathrm{M}}-C_{\mathrm{G}}-C_{\mathrm{I}},
$$

where

$E$ - the economic effect that is to be determined as the difference between the city's total revenues under the effect of creative and cultural industry cluster and investments in the development;

$T R_{\mathrm{Cl}}$ - total revenue from cluster organisations received from various products and services in the urban environment and beyond;

$\Delta R_{\mathrm{T}}$ - additional revenue received through tourist clusters, which includes the hotel service industry, attracting additional guests to the city, oriented towards the consumption of products offered within the city cluster; $\Delta R_{\mathrm{U}}$ - additional income received by urban universities from the growing number of students (including those students who have begun studies for a particular period of time but have not continued and have remained in the city due to the attractiveness of the environment);

$\Delta R_{\mathrm{I}}$ - additional income received by firms using innovative or new approaches in their creative activity in a creative environment, where creative and progressive workforce is attracted to the urban environment and works with higher productivity;

$\Delta R_{\operatorname{Tr}}$ - additional revenue received by transport companies in servicing growing urban traffic;

$\Delta R_{\mathrm{Eu}}$ - additional income received as a result of the urbanisation of the city (demographic growth contributes to the growth of the urban economy);

$C_{\mathrm{M}}$ - consumption of urban households, which is related to the output of guests (guest artists, guest lecturers, etc.) within the creative and cultural industries in the urban environment;

$C_{\mathrm{G}}$ - city management (municipality) expenditure to support the purchase of products or services from cluster organisations beyond the city's territorial boundaries;

$C_{\mathrm{I}}$ - the investment costs necessary to import products or services.

The following is necessary to formulate the methodology for calculating each component:

$T_{\mathrm{RCl}}-$ revenues minus expenses, or final financial results before tax, the basis of the entire business organisation accounting of an entity. A cluster evaluation would be in the local national currency.

Additional revenue generated from tourist activity, $\Delta R T$ - can be evaluated using two formulas (6) and (7):

$$
\Delta R_{\mathrm{T}}=Q_{\mathrm{T}} \cdot P_{\mathrm{A}},
$$

where 
$Q_{\mathrm{T}}$ - a number of tourists who have attended events, concerts organised by the industrial members of the creativity and cultural cluster;

$P_{\mathrm{A}}-$ an average annual revenue received by cluster institutions or organisations from one tourist.

$$
\Delta R_{\mathrm{T}}=Q_{\mathrm{T}} \cdot\left(P_{\mathrm{T}}+N \cdot P_{\mathrm{Ho}}+N \cdot P_{\mathrm{L}}\right),
$$

where

$P_{\mathrm{T}}-$ the price of the average event ticket in the local national currency;

$P_{\mathrm{Ho}}-$ average living expenses for a single visitor in the local national currency;

$P_{\mathrm{L}}-$ an average price for dinner at a local restaurant in local currency;

$N$ - an average number of days spent by a single visitor in the city.

$\Delta R_{\mathrm{U}}$ - can be estimated by formula (8):

$$
\Delta R_{\mathrm{U}}=Q_{\mathrm{VCS}} \cdot F_{\mathrm{VC}} \cdot K_{\mathrm{R}}+Q_{\mathrm{FS}} \cdot F_{\mathrm{F}} \cdot K_{\mathrm{F}},
$$

where

- $Q$ vcs - a number of students who have entered the city's higher education institutions from other cities;

- $\quad F_{\mathrm{VC}}-$ an average annual cost of studying for a local student from another city;

- $K_{\mathrm{R}}-$ a coefficient, which evaluates the significance of a particular city's creative environment by attracting students from other cities (excluding the influence of other factors);

- $Q_{\mathrm{FS}}$ - a number of students enrolled in higher education institutions in the city from other countries;

- $F_{\mathrm{F}}-$ an average tuition fee for a foreign student in local currency;

- $K_{\mathrm{F}}-$ a coefficient that assesses the significance of a particular city's creative environment by attracting students from other countries (excluding the influence of other factors).

The attractiveness coefficients of creativity and cultural cities are determined in the following range:

1) $0<K_{\mathrm{R}}<0.3$;

2) $0<K_{\mathrm{F}}<0.5$.

$\Delta R_{\mathrm{I}}$ can be estimated using formula (9):

$$
\Delta R_{\mathrm{I}}=\sum_{i=1}^{n} K_{i} \cdot P_{i}
$$

where 
$K_{i}$ - the coefficient that evaluates the importance of innovative aspect to the growth of the corresponding sector, while totally separated from the influence of other factors;

$P_{i}$ - minus expenses - the final financial result before tax, expressed on the basis of the entire account of the entity's business transactions, obtained in the local creative area of the city in local currency.

Factors that affect profit in the creative industries, with the exception of the effects of the culture and creativity environment:

1) the growth of demand for industry products;

2) increase in labour productivity, which has been stimulated by changes in the technological process (innovations);

3) increase in labour productivity, which has been promoted by the change of leadership style;

4) increase in labour productivity, which has been promoted by raising qualification.

The coefficient that assesses the importance of innovative approaches to the growth of $i$-th creative industries is between 0.01 and 0.15 .

$\Delta R_{\mathrm{Eu}}$ is calculated using the same methodology approach as $\Delta R_{\mathrm{I}}$. In this case, the value of the coefficient will be in the range of 0.005 to 0.01 .

$\Delta R_{\operatorname{Tr}}$ can be estimated using formula (10) or (11):

$$
\Delta R_{\mathrm{Tr}}=Q_{\mathrm{T}} \cdot P_{\mathrm{Txp}} \cdot Q_{\mathrm{Txp}} \cdot N,
$$

where

$Q_{\mathrm{T}}$ - a number of tourists (guests) (people) who have attended events, concerts organised by the industrial members of the creativity and cultural cluster;

$P_{\text {Txp }}$ - an average ticket price for public transport per trip in local currency;

$Q_{\text {Txp }}$ - an average number of trips per visitor per day;

$N$ - an average number of days spent by a single visitor in the city.

$$
\Delta R_{\mathrm{Tr}}=Q_{\mathrm{TT}} \cdot P_{\mathrm{Txp}} \cdot Q_{\mathrm{Txp}} \cdot N \cdot K_{\mathrm{T}}
$$

where

$Q_{\mathrm{TT}}$ - the total number of visitors (tourists) per city in a year;

$K_{\mathrm{T}}-$ a coefficient that evaluates the role of creativity in attracting visitors (tourists) to the city, separating the influence of all other factors that make city attractive.

Other factors that influence the flow of visitors (tourists) to the city are as follows:

1) international recognition of the city;

2) the number of significant objects in the urban environment;

3) the existence of local and internationally recognised tourism destinations in the city's territory;

4) the distance to the international transport transit point. 
The coefficient $C_{\mathrm{M}}$, which assesses the role of creativity in attracting visitors (tourists) in the city, and exempt of all other factors that makes the city attractive, is estimated to range from 0.01 to 0.3 .

The $C_{\mathrm{M}}$ can be evaluated as follows:

$$
C_{\mathrm{M}}=Q_{\mathrm{Ev}} \cdot S \cdot P_{\mathrm{Ev}} \cdot S_{\mathrm{I}},
$$

where

$Q_{\mathrm{Ev}}$ - a number of events and concerts organised by foreign organisations in the domain of cultural and creative industries;

$S$ - capacity of events and concert venues (number of places);

$P_{\mathrm{Ev}}$ - the price of the average event or concert ticket in local currency;

$S_{\text {I }}$ - proportion of population of the given city in the number of visitors to the total event or concert.

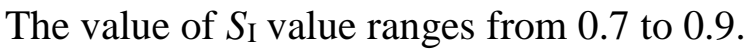

City administration (municipality) expenditure to support the purchase of cluster organisation products or services beyond the city's territorial boundaries $\left(C_{\mathrm{G}}\right)$, to promote the provision of economic and technical processes in city institutions, consists of goods and services produced by organisations registered outside city jurisdiction.

The $C_{\mathrm{I}}$ can be evaluated as follows:

$$
C_{\mathrm{I}}=\sum_{i=1}^{n} E_{i}+\sum_{i=1}^{n} C_{i}
$$

where

$E_{i}$ - expenses of various commercial organisations and nongovernmental organisations in the creativity and cultural industry to purchase the necessary equipment, technical aids, technologies, software, etc., outside the city's economic framework, expressed in local currency;

$C_{i}$ - expenses of various forms of commercial and non-governmental organisations that are related to the construction, reconstruction, restoration, overhaul, communications construction and other construction work outside the city's economic framework, expressed in local currency.

According to the authors, in order to make presented detailed calculations, it is necessary to involve administrative resources of the city, i.e., to create a demand mechanism, both from analysts employed in the administrative resource of the city and from the statisticians of the businesses and organizations involved in domain to receive detailed and solid modelling data. 


\section{MODELLING THE ECONOMIC EFFECT IN TWO CITIES}

The authors have carried out modelling of the economic effect of two imagined cities: $\mathbf{J}$ and $\mathrm{K}$. In the first city $\mathbf{J}$, it was assumed that the population is larger and the economic potential of creativity and cultural cluster growth is faster, while the economic potential of creativity and culture clusters is slower in the city $\mathrm{K}$. It is assumed that $\mathrm{K}$ does not have any higher education institution.

At the beginning of modelling, $\Delta R_{\mathrm{T}}$ is calculated - additional income received through tourism clusters, which includes the hotel service industry, attracting additional guests to the city that are oriented towards the consumption of the products offered by the existing city cluster. The authors of the paper have made calculations based on the two formulas (6) and (7), with close results. The result of the subsequent economic effect is calculated using formula (7) (see Table 1).

Table 1. Additional Calculation of Income $\Delta \mathrm{R}_{\mathrm{T}}$ from Tourism Clusters (developed by the authors)

\begin{tabular}{|l|l|l|l|l|l|l|l|l|}
\hline & $Q_{\mathrm{T}}$ & $P_{\mathrm{A}}$ & $P_{\mathrm{T}}$ & $P_{\mathrm{Ho}}$ & $P_{\mathrm{L}}$ & $N$ & $\Delta R_{\mathrm{T}}(9)$ & $\Delta R_{\mathrm{T}}(10)$ \\
\hline City J & $121000^{*}$ & 152 & 10 & 40 & 10 & 3 & 18392000 & 19360000 \\
\hline City K & 16000 & 98 & 10 & 40 & 8 & 2 & 1568000 & 1696000 \\
\hline
\end{tabular}

Since, according to the assumption, there are no higher education institutions in the city $\mathrm{K}$, then $\Delta R_{\mathrm{U}}$ (additional income received by city universities from the growing number of students) is 0 (see Table 2).

Table 2. Additional Calculation of the Revenue from Growing Number of Students $\Delta R_{\mathrm{U}}$ (developed by the authors)

\begin{tabular}{|l|l|l|l|l|l|l|l|}
\hline & $Q_{\mathrm{VCS}}$ & $F_{\mathrm{VC}}$ & $K_{\mathrm{R}}$ & $Q_{\mathrm{FS}}$ & $F_{\mathrm{F}}$ & $K_{\mathrm{F}}$ & $\Delta R_{\mathrm{U}}$ \\
\hline City J & 30000 & 2300 & 0.27 & 5000 & 8000 & 0.15 & 24630000 \\
\hline City K & 0 & 0 & 0 & 0 & 0 & 0 & 0 \\
\hline
\end{tabular}

$\Delta R_{\operatorname{Tr}}$ (additional income received by transport companies in servicing growing traffic) is calculated from the two formulas (10) and (11), while value calculated with formula (10) is used in the modelling of the economic effect (see Table 3).

Table 3. Additional Calculation of Revenue from Traffic Flow $\Delta R_{\operatorname{Tr}}$ (developed by the authors)

\begin{tabular}{|l|l|l|l|l|l|l|l|l|}
\hline & $Q_{\mathrm{T}}$ & $P_{\operatorname{Txp}}$ & $Q_{\operatorname{Txp}}$ & $N$ & $\Delta R_{\operatorname{Tr}}(13)$ & $Q_{\mathrm{TT}}$ & $K_{\mathrm{T}}$ & $\Delta R_{\operatorname{Tr}}(14)$ \\
\hline City J & 121000 & 1 & 6 & 3 & 2178000 & 500000 & 0.23 & 2070000 \\
\hline City K & 16000 & 1 & 2 & 2 & 64000 & 130000 & 0.12 & 62400 \\
\hline
\end{tabular}

The city $\mathrm{J}$ significantly exceeds the calculated $C_{\mathrm{M}}$ (consumption of urban households, which is related to the output of guests (guest artists, guest lecturers,

${ }^{*}$ Here and thereafter, the estimated data needed for calculations are indicated gray. 
etc.) within the creative and cultural industries in the urban environment), while in the city $\mathrm{M}$ it is relatively less (see Table 4).

Table 4. Creativity Roles for Attracting Tourist CM Calculation (developed by the authors)

\begin{tabular}{|l|l|l|l|l|l|}
\hline & $Q_{\text {Ev }}$ & $S$ & $P_{\text {Ev }}$ & $S_{\mathrm{I}}$ & $C_{\mathrm{M}}$ \\
\hline City J & 58 & 5000 & 60 & 0.7 & 12180000 \\
\hline City K & 3 & 600 & 25 & 0.8 & 36000 \\
\hline
\end{tabular}

Effect for several characteristics area included indicative difference for both situations further (see Table 5). The increase in a city income can be identified with connection of developments of creative and cultural cluster.

Table 5. Increase of the Income from an Innovative or New Approach in a Creative Environment, $\Delta R_{\mathrm{I}}$ Calculation (developed by the authors)

\begin{tabular}{|c|c|c|c|c|c|c|}
\hline & $\begin{array}{l}\text { K1 } \\
\text { (NACE A) }\end{array}$ & $\begin{array}{l}P 1 \\
\text { (NACE A) }\end{array}$ & $\begin{array}{l}\text { K2 } \\
\text { (NACE C) }\end{array}$ & $\begin{array}{l}P 2 \\
\text { (NACE C) }\end{array}$ & $\begin{array}{l}\text { K3 } \\
\text { (NACE E) }\end{array}$ & $\begin{array}{l}P 3 \\
\text { (NACE E) }\end{array}$ \\
\hline City J & 0.01 & 500000 & 0.12 & 3000000 & 0.01 & 700000 \\
\hline \multirow[t]{2}{*}{ City K } & 0.01 & 40000 & 0.11 & $500 \quad 000$ & 0.01 & 80000 \\
\hline & $\begin{array}{c}K 4 \\
(\mathrm{NACE} F)\end{array}$ & $\begin{array}{c}P 4 \\
(\text { NACE F) }\end{array}$ & $\begin{array}{c}K 5 \\
\text { (NACE G) }\end{array}$ & $\begin{array}{c}P 5 \\
\text { (NACE G) }\end{array}$ & $\begin{array}{c}K 6 \\
\text { (NACE H) }\end{array}$ & $\begin{array}{c}P 6 \\
\text { (NACE H) }\end{array}$ \\
\hline City J & 0.14 & 6000000 & 0.02 & 2000000 & 0.02 & 1500000 \\
\hline \multirow[t]{2}{*}{ City K } & 0.14 & 50000 & 0.02 & 50000 & 0.02 & 15000 \\
\hline & $\begin{array}{c}\text { K7 } \\
\text { (NACE I) }\end{array}$ & $\begin{array}{c}P 7 \\
\text { (NACE I) }\end{array}$ & $\begin{array}{c}K 8 \\
(\mathrm{NACE} \mathbf{J})\end{array}$ & $\begin{array}{c}P 8 \\
(\mathrm{NACE} J)\end{array}$ & $\begin{array}{c}K 9 \\
\text { (NACE K) }\end{array}$ & $\begin{array}{c}P 9 \\
\text { (NACE K) }\end{array}$ \\
\hline City J & 0.13 & 30000000 & 0.07 & 10000000 & 0.06 & 5000000 \\
\hline \multirow[t]{2}{*}{ City K } & 0.13 & 2000000 & 0.06 & 500000 & 0.02 & 100000 \\
\hline & $\begin{array}{c}\text { K10 } \\
\text { (NACE L) }\end{array}$ & $\begin{array}{c}P 10 \\
(\text { NACE L) }\end{array}$ & $\begin{array}{c}\text { K11 } \\
\text { (NACE M) }\end{array}$ & $\begin{array}{c}P 11 \\
\text { (NACE M) }\end{array}$ & $\begin{array}{c}K 12 \\
\text { (NACE O) }\end{array}$ & $\begin{array}{c}P 12 \\
(\mathrm{NACE} \text { O) }\end{array}$ \\
\hline City J & 0.08 & 30000000 & 0.14 & 90000000 & 0.01 & 2000000 \\
\hline \multirow[t]{2}{*}{ City K } & 0.02 & 1500000 & 0.08 & 4000000 & 0.01 & 20000 \\
\hline & $\begin{array}{c}K 13 \\
\text { (NACE P) }\end{array}$ & $\begin{array}{c}P 13 \\
\text { (NACE P) }\end{array}$ & $\begin{array}{c}K 14 \\
\text { (NACE Q) }\end{array}$ & $\begin{array}{c}P 14 \\
\text { (NACE Q) }\end{array}$ & $\begin{array}{c}K 15 \\
\text { (NACE R) }\end{array}$ & $\begin{array}{c}P 15 \\
\text { (NACE R) }\end{array}$ \\
\hline City J & 0.10 & 1000000 & 0.03 & 60000 & 0.14 & 30000000 \\
\hline \multirow[t]{2}{*}{ City K } & 0.07 & 19000 & 0.02 & 1600 & 0.14 & 35000 \\
\hline & $\begin{array}{c}\text { K16 } \\
\text { (NACE S) }\end{array}$ & $\begin{array}{c}P 16 \\
\text { (NACE S) }\end{array}$ & $\begin{array}{c}\text { K17 } \\
\text { (NACE T) }\end{array}$ & $\begin{array}{c}P 17 \\
(\text { NACE T) }\end{array}$ & & $\Delta R_{\mathrm{I}}$ \\
\hline City J & 0.06 & 1000000 & 0.14 & 2000000 & & 25843800 \\
\hline City K & 0.06 & 20000 & 0.14 & 160000 & & 780662 \\
\hline
\end{tabular}

The additional economic effect related to the effect from urbanisation with increase of social life for the modelled sample also indicates an increase. Model calculations prove that the calculated income (see Table 6), which can be attributed to urbanisation effect, is larger for the city $\mathrm{J}$ that supports the model. 
Table 6. Additional Income Calculation from Urbanisation $\Delta R_{\mathrm{Eu}}$ (developed by the authors)

\begin{tabular}{|c|c|c|c|c|c|c|}
\hline & $\begin{array}{c}K 1 \\
(\mathrm{NACE} A)\end{array}$ & $\begin{array}{c}P 1 \\
(\text { NACE A) }\end{array}$ & $\begin{array}{c}\text { K2 } \\
\text { (NACE C) }\end{array}$ & $\begin{array}{c}P 2 \\
\text { (NACE C) }\end{array}$ & $\begin{array}{c}\text { K3 } \\
\text { (NACE E) }\end{array}$ & $\begin{array}{c}P 3 \\
\text { (NACE E) }\end{array}$ \\
\hline City J & 0.005 & 125000 & 0.010 & 750000 & 0.005 & 125000 \\
\hline \multirow[t]{2}{*}{ City K } & 0.005 & 10000 & 0.010 & 130000 & 0.005 & 15000 \\
\hline & $\begin{array}{c}K 4 \\
(\mathrm{NACE} \text { F) }\end{array}$ & $\begin{array}{c}P 4 \\
(\text { NACE F) }\end{array}$ & $\begin{array}{c}\text { K5 } \\
\text { (NACE } \\
\text { G) }\end{array}$ & $\begin{array}{c}P 5 \\
\text { (NACE } \\
\text { G) }\end{array}$ & $\begin{array}{c}\text { K6 } \\
\text { (NACE } \\
\text { H) } \\
\end{array}$ & $\begin{array}{c}\text { P6 } \\
\text { (NACE } \\
\text { H) }\end{array}$ \\
\hline City J & 0.007 & 2000000 & 0.005 & 1500000 & 0.005 & 800000 \\
\hline \multirow[t]{2}{*}{ City K } & 0.007 & 40000 & 0.005 & 21000 & 0.005 & 20000 \\
\hline & $\begin{array}{c}\text { K7 } \\
\text { (NACE I) }\end{array}$ & $\begin{array}{c}P 7 \\
\text { (NACE I) }\end{array}$ & $\begin{array}{c}K 8 \\
\text { (NACE J) }\end{array}$ & $\begin{array}{c}P 8 \\
(\mathrm{NACE} J)\end{array}$ & $\begin{array}{c}\text { K9 } \\
\text { (NACE } \\
\text { K) }\end{array}$ & $\begin{array}{c}P 9 \\
\text { (NACE } \\
\text { K) }\end{array}$ \\
\hline City J & 0.009 & 7000000 & 0.007 & 3000000 & 0.008 & 1750000 \\
\hline \multirow[t]{2}{*}{ City K } & 0.009 & 1000000 & 0.005 & 80000 & 0.006 & 63000 \\
\hline & $\begin{array}{c}\text { K10 } \\
\text { (NACE L) }\end{array}$ & $\begin{array}{c}P 10 \\
(\text { NACE L) }\end{array}$ & $\begin{array}{c}K 11 \\
\text { (NACE M) }\end{array}$ & $\begin{array}{c}P 11 \\
\text { (NACE M) }\end{array}$ & $\begin{array}{c}\text { K12 } \\
\text { (NACE } \\
\text { O) }\end{array}$ & $\begin{array}{c}P 12 \\
\text { (NACE } \\
\text { O) }\end{array}$ \\
\hline City J & 0.009 & 9000000 & 0.010 & 27000000 & 0.005 & 600000 \\
\hline \multirow{2}{*}{ City K } & 0.007 & 1000000 & 0.008 & 1357000 & 0.005 & 5000 \\
\hline & $\begin{array}{c}\text { K13 } \\
\text { (NACE P) }\end{array}$ & $\begin{array}{c}P 13 \\
\text { (NACE P) }\end{array}$ & $\begin{array}{c}\text { K14 } \\
\text { (NACE } \\
\text { Q) } \\
\end{array}$ & $\begin{array}{c}P 14 \\
\text { (NACE } \\
\text { Q) }\end{array}$ & $\begin{array}{c}\text { K15 } \\
\text { (NACE R) }\end{array}$ & $\begin{array}{c}P 15 \\
\text { (NACE R) }\end{array}$ \\
\hline City J & 0.008 & 321000 & 0.006 & 21000 & 0.009 & 11000000 \\
\hline \multirow[t]{2}{*}{ City K } & 0.008 & 41000 & 0.006 & 121 & 0.009 & 1000000 \\
\hline & $\begin{array}{c}\text { K16 } \\
\text { (NACE S) }\end{array}$ & $\begin{array}{c}P 16 \\
\text { (NACE S) }\end{array}$ & $\begin{array}{c}\text { K17 } \\
\text { (NACE T) }\end{array}$ & $\begin{array}{c}P 17 \\
\text { (NACE T) }\end{array}$ & & $\Delta R_{\mathrm{Eu}}$ \\
\hline City J & 0.005 & 346000 & 0.008 & 681000 & & 595122 \\
\hline City K & 0.006 & 59000 & 0.008 & 19881 & & 39411 \\
\hline
\end{tabular}

Table 7 demonstrates the economic effect, which is to be calculated as the difference between the city's total income from the cluster of creative and cultural industries and taking into account investment in the development of the clusters mentioned above for cities $\mathrm{J}$ and $\mathrm{K}$.

Table 7. Calculation of the Economic Effect (developed by the authors)

\begin{tabular}{|l|l|l|l|l|l|}
\hline & \multicolumn{1}{|c|}{$E$} & \multicolumn{1}{|c|}{$T R_{\mathrm{Cl}}$} & \multicolumn{1}{c|}{$\Delta R_{\mathrm{T}}$} & \multicolumn{1}{|c|}{$\Delta R_{\mathrm{U}}$} & \multicolumn{1}{c|}{$\Delta R_{\mathrm{I}}$} \\
\hline City J & 60976922 & 2000000 & 19360000 & 24630000 & 25843800 \\
\hline City K & 1294073 & 800000 & 1696000 & 0 & 780662 \\
\hline & $\Delta R_{\mathrm{Tr}}$ & $\Delta R_{\mathrm{Eu}}$ & $C_{\mathrm{M}}$ & $C_{\mathrm{G}}$ & $C_{\mathrm{I}}$ \\
\hline City J & 2178000 & 595122 & 12180000 & 1200000 & 250000 \\
\hline City K & 64000 & 39411 & 36000 & 2000000 & 50000 \\
\hline
\end{tabular}

The summary economic effect for modelled sample indicates an increase in city economy with focus on creative and cultural cluster development versus a stagnant city situation. Model calculations prove that income, which is generated by 
development of creative and cultural industry cluster, is a more valuable development strategy. For particular city data in calculations, particular data would have to be assessed and detailed analysis models utilised to adopt for a particular situation. The adapted models would better indicate alignment with long-term development initiative targets and improve achievement rates for the support of planning and later ensure full integration of the cultural and creative sector activity sources into urban economy providing necessary infrastructure. It also would help assess funding alternatives of investments needed. Model usage to assess different cities would provide comparable Key Performance Indicators (KPIs) to compare cultural and creative sector contribution to city economies and together with historical data also would provide basis for further model improvements.

\section{URBAN NETWORK}

Urban network, organized on the creative and cultural industries cluster, can lead to the emergence of new factors in the long-term development:

1) urban environment as place where the creative resources are accumulated and capitalised can stop the drain of youth from a particular city and in future facilitate the inflow of new specialists from other cities;

2) the intensity of cultural activities and their presentation contribute to the recognition of creative resources in foreign markets of the city, as well as support competitiveness in the internal markets, attract material and non-material flows, such as tourists, capital, and increase growth of economic activity;

3 ) the growth of economic activity in the domain of creativity and cultural industries provides a structural shift in the economy - the transition to a higher technological level.

The strategy is of great importance for growth; a strategy is a compromise of interests. Each city includes indications of various desires and interests - political, age, neighborhood, national, etc. The scenarios for socio-economic development of many cities are based on a different set of indicators, depending on the activities that are identified as necessary in the process for improving the urban environment, as well as in developing the strategy with public participation. The strategy is the highest reference point in planning for economic processes in the urban environment. The strategy should define a logical structure for social and economic planning processes, while minimising the use of municipality's financial resources and supporting development of cooperation models with third parties for the budget process. Still many urban strategies approved turn out to be a manifestation of socioeconomic policies and are often not implemented or are delayed. Effectively implemented strategies fulfill two important management functions:

1) they approve a city development scenario as optimal from the point of view of the municipality and taking into account the existing resources and possibilities of the city; 
2) they support development of guidelines that are included in the action plan, which should serve as a description of the activities that will enable the city to implement the chosen scenario.

The strategy serves as an investment attractiveness factor for the city. The existence of a plan for urban development has a beneficial effect on the choice of investors and thus increases the rating of investment climate. The strategy is an opportunity for the urban community to consolidate and to address the most significant challenges. The strategy is a collective task. Each of the city's public forces occupies a specific responsibility and role in the implementation of the tasks:

1) municipality agencies form the regulatory and legal framework that ensures the implementation of strategy (planning processes related to the socio-economic development of the city) and oversees implementation of city-specific targeted programs;

2) business - the foundation of local government development, job creation, implementation of investment projects, participation in city social programs, etc.;

3) residents - active participation in city life, affecting the local territorial location, the attachment of the city (patriotism) and improving living standard.

The authors emphasise the following:

1) the existence of a strategy might not fully cover all development areas; it indicates the most important or necessary directions to reach strategic goals;

2) strategic directions are not autonomous or independent from each other, they are closely related; it is a complex set of activities towards achieving the strategic goals.

When developing possible strategies for urban development, a situation may arise that the options in a city development are limited. Priority strategic areas must be designed in such a way that they compile for the effects of a structured system (see Fig. 1).

Ensuring support for strategic areas of the creative and cultural cluster, region or city can increase economical contribution for this cluster in the overall area economy.

Cities and directly adjacent territories are considered as linked socio-economic systems for analysis. They have the following characteristics:

1) high population density;

2) administrative and territorial specifics;

3) defined mission of city, which is multifunctional, and it is shaped by the city itself (both for the broader administrative territorial unit, the city comprising the city and the city's inhabitants);

4) high level of service, which allows the city utility companies to service not only urban residents, but also inhabitants of areas in a radius of approximate $50 \mathrm{~km}$;

5) a network of utility service infrastructure, which ensures higher level of the satisfaction of the needs of adjacent territories. 


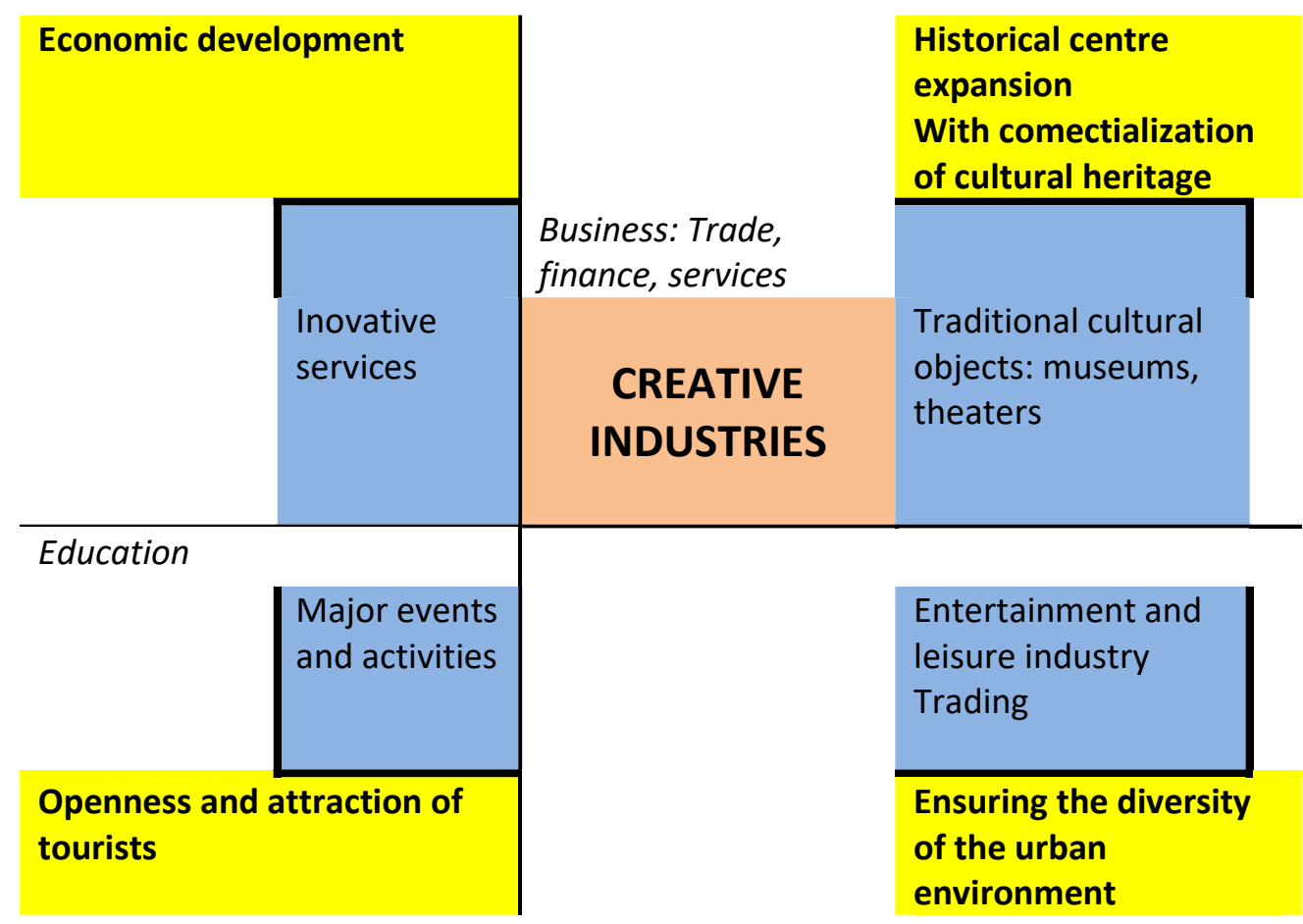

Fig. 1. Strategic interaction of creative industries (developed by the authors).

Nowadays people are often motivated by factors that are not included in purely economic categories (such as high quality food, availability of health and education, safety, good working conditions, leisure opportunities, etc.) (Paula, 2008).

\section{CONCLUSION}

The assessment of the cluster potential for the creative and cultural industries is important for the economic analysis of territory development. Potential of cluster can be analysed using the employment level in the cluster, comparing it with the overall level of the city, as well as the employment growth rate in the cluster, comparing it with employment in the urban economy and the cluster product share in the urban product (the total value added generated by the urban economy).

The base of the creative or cultural industry is based on the exclusion principle, which is targeted by the substitution denial and limited availability. In order to invest in the development of a creative city cluster and with the new economic approach, it is necessary to evaluate the economic utility of particular clusters in a given area.

All cluster formations benefit from the localisation effect - all organisations gain from the availability of other entities when using common or similar intermediate factors of production, as well as using creative workforce to achieve an effect of synergies. 
With a cabinet analysis method and evaluating publicly available information of the cultural organisations in cities and their financial performance for a five-year period, it has been concluded that the financial flow consists not only of income from the inhabitants of a particular city, but also of the whole population of the respective region or agglomeration.

A thoughtful, proactive and logical marketing plan for a particular area can encourage a new visitor flow from near territories, other regions and even countries to increase total demand within a particular territorial unit, thus supporting economic growth.

City functions should be distinguished by two aspects - internal (urban) and external (city serving). The internal aspect must ensure the conditions of integrative functioning and development, the external aspect implies that the city is part of the territorial employment chain and has responsibilities to other parts of the overall country socio-economic system.

\section{REFERENCES}

Cabinet of Ministers of the Republic of Latvia. (2004). On the Statistical Regions of the Republic of Latvia and the Administrative Units of the Republic of Latvia, No 28 of April 28, 2004. Retrieved 19.07.2019 from http://likumi.lv/doc.php?id=88074

Central Statistical Bureau of Latvia. (2017). Statistical Classification of Economic Activities in the European Community, $2^{\text {nd }}$ ed. Retrieved 19.07.2019 from: http://www.csb.gov.lv/node/29900/list/4/0

Howkins, J. (2013). The Creative Economy: How People Make Money from Ideas. UK: Penguin, pp. $26-34$.

Howkins, J. (2013). The Creative Economy. Retrieved 19.07.2017 from http://www.creativeeconomy.com/john.htm

Kipnis, B. A. (2006). A World City, Psychological Rewards and the Creative Agencies. $\begin{array}{llll}\text { Loughborough } & \text { University. } & \text { Retrieved } & 19.07 .2019\end{array}$ http://www.lboro.ac.uk/gawc/rb/rb207.html

Matarasso, F., Lendry, C. (1999). Balancing Act: Twenty-one Strategic Dilemmas in Cultural Policy. Council of Europe, pp. 12-13.

Paula, L. (2008). Tautas attīstība - ko tas nozīmē? Latvijas Vēstneša portāls par likumu un valsti. Retrieved 19.07.2019 from http://www.lvportals.lv/visi/likumi-prakse?id=170248 (in Latvian)

Stepanov, A. A., et al. (2013). Creative Class and problems of development of innovation systems in economy. Moscov: Russian State Social University, pp. 41-43.

UN-Habitat. (2016). World cities report 2016. Retrieved 19.07.2019 from http://wcr.unhabitat.org/main-report

Wilson, E. (2002). The Glamorous Outcast. New Brunswick, New Jersey: Rutgers University Press, pp. 28-36.

\section{AUTHORS' SHORT BIOGRAPHIES}

Kaspars Plotka, Mg. oec., obtained the degree of Bachelor of Science in Business Administration and Management in 2005 (Business Institute "RIMPAK Livonija"). In 2017, he obtained the Professional Master's degree in Urban and Regional Engineering Economics. He is a Lecturer, a PhD student and Researcher within the Institute of Civil Engineering and Real Estate Economics, Faculty of Engineering Economics and Management, Department of Territorial Development Management and Urban Economics, Riga Technical University. He is the author and co-author of more than 20 scientific publications. His main research areas are the intellectual urban environment, 
the concept of a city, urban management, risk management, TQM, ecological economics, the evaluation of synergy, etc.

E-mail: Kaspars.Plotka@rtu.lv

ORCID iD: http://orcid.org/0000-0001-9440-8215

Jānis Viržbickis, Dr. math., Assistent Professor of the Faculty of Business, Management and Economics, University of Latvia. He delivers lectures at the Faculty of Business, Management and Economics. Before RTTEMA was included in the University of Latvia, he was working as an Assistant Professor at RTTEMA Business Department. From 2003 to 2013 he was the Head of RTTEMA Department of Economics and Business. Prior to his work at RTTEMA, he was Researcher and Laboratory Head at the Institute of Mathematics and Informatics of the University of Latvia. He is the author of more than 40 scientific articles in mathematics and economics. J.Viržbickis regularly attends international scientific conferences and seminars.

E-mail: Janis.Virzbickis@lu.lv

Jānis Zvirgzdiñ̌s, Mg. oec., obtained the degree of Bachelor of Electrical Science in 2015. In 2018, he obtained the Professional Master's degree in Urban and Regional Engineering Economics and earned the qualification of an Economist. He is a Researcher and a PhD student within the Institute of Civil Engineering and Real Estate Economics, Faculty of Engineering Economics and Management, Riga Technical University. His main research areas are green economy, circular economy, sustainable development, intellectual urban environment, renewable and nuclear energy and real estate management. He received the Award in Final Paper Competition of the Latvian Association of Power Engineers and Energy Constructors in 2015.

E-mail: Janis.Zvirgzdins_1@ @rtu.lv

ORCID iD: http://orcid.org/0000-0001-6677-0145

Girts Zariňš, Mg. oec., Scientific Assistant at Riga Technical University, graduated MBA RTU 2005. G. Zarins has been working as a Lecturer at RTU since 2018 and conducting research in the areas of city economic, modelling, growth and sustainable development.

E-mail: Girts.Zarins_1@rtu.lv

ORCID iD: https://orcid.org/0000-0002-4719-0126

Sanda Geipele, Dr. oec, Assoc. Prof., Riga Technical University, Latvia. Work experience has been acquired both in the private sector and in public administration, including real estate tax administration for several years at Riga City Council's Municipal Revenue Department. Research interests: sustainability development problems of real estate market, household resource management, construction industry, including land use management and institutional economics. She is the author and co-author of more than 60 scientific publications, including scientific monograph "Management System of Real Estate Market Development in Latvia" (2015) and two monographs with co-authors. She is an expert in management and economic sciences of the Latvian Council of Science.

E-mail: Sanda.Geipele@rtu.lv

ORCID iD: http://orcid.org/0000-0002-4721-5944 